\title{
Gênero e migrações na histónia entre Brasil e Itália: uma entrevista com Chiara Vangelista
}

\author{
Cristina Scheibe Wolff \\ Universidade Federal de Santa Catarina \\ Joana Maria Pedro \\ Universidade Federal de Santa Catarina
}

\begin{abstract}
Chiara Vangelista é professora de História da América Latina da Faculdade de Ĺngua e Literatura Estrangeira da Universidade degli Studi di Genova. Formada em Ciências Polític as, suas muitas pesquisas trata ram de temas relativos às fronteiras e migrações. Esses estudos iniciaram-se com a abordagem da imigração no Brasil, ampliando-se depois o leque dessas disc ussões para diferentes formas de migrações. Desde seus primeiros estudos, a s mulherese o gênero sã o temas de destaque que aparecem interconectados com a história da imigração, do estabelecimento de fronteiras, do trabalho e da ruralidade. A história oral, com uma perspectiva etnográfica, e também a utilização de imagens ta is como as fotos publicadas por padres italianos para promover a imigração, sempre com uma mirada crítica, também são ca ra c terístic as de seu tra ba lho. Entre seus p rinc ipa is livros estã o Os braços da lavoura: imigrantes e caipiras na formação do merca do de trabalho paulista (1850-1930), public a do na Itália em 1982 e no Brasil em 1991, em São Paulo, pela Hucitec; Terra, etnie, migrazioni. Tre donne nel Brasile contemporâneo (Il Segnalibro, 1999); e Confini e frontiere. Conflitti e alleanze inter-etniche in Americ a meridionale (sec. XVIII) (II Segnalivor, 2001). Chia ra Vangelista é fundadora e responsá vel pelo Projeto
\end{abstract}

Copyright $\propto 2007$ by Revista Estudos Feministas 


\section{CRISTINA SC HEIBE WO LFF E J OANA MARIA PEDRO}

Mujeres - Red Intemacional para el Estudio del Género en America Latina (http://www.mujeres.it).

Esta entrevista foi realiza da em sua visita a o Instituto de Estudos de Gênero da Universida de Federal de Santa Catarina e nela procuramos explorar a trajetória dessa intelectual que tem feito muitas viagens entre o Brasil e a Itália. Além de falar de seus estudos, seus temas de pesquisa e das lutas levadas pelas mulheres acadêmicas na Itália, especialmente com relação aos estudos de gênero, Chiara Vangelista discorre também sobre a construção da Rede Mujerese sobre aspectos das migrações contemporâneas de mulheres latinoa mericanas para a Itália.

Outra questão que se destaca na entrevista é a a bordagem de gênero e memória. Chia ra mostra, a tra vés de exemplos de sua pesquisa, de que maneira as na rrativa sora is focalizam o corpo como um "mapa das origens", as relações entre entrevistada e entrevistadora e, a inda, a forma como os acontecimentos do presente definem trajetórias para as narrativas. Enfim, sua entrevista nos ajuda a refletir sobre a maneira como as temáticas de histórias das mulheres e do gênero têm sido leva daspela pesquisa dora ita lia na, as tensões entre pesquisadoras que usam essas categorias e a forma como a memória tem sido abordada em sua intersecção com as relações de gênero. 
Joana Maria Pedro: Então, Chiara, o que a Cristina e eu estamos querendo saber é um pouco da tua história de vida. Um pouco da tua história profissional, intelectual. Como é que tu chegaste a o estudo sobre mulheres e gênero?

Chiara Vangelista: Comecei minha trajetória na Universidade de Turim, fazendo pesquisas sobre processos migratórios e relações inter-étnic as na fronteira brasileira. De fato eu comec ei a ter interesse sobre questões de gênero graças à insistência de a migas minhas que tinham um grupo de trabalho na minha faculdade, que naquele momento era a Faculdade de Ciências Políticas, na Universidade de Turim. Esse grupo, que se chamava Temáticas Femininas, começou a atuar na primeira metade dos anos 80 e terminou no início dos 90 . Era um grupo muito interessante, porque lutou muito para introduzir nas aulas da minha faculdade a temática de gênero. Para sintetizar: esse grupo propunha cada ano uma série de temáticas de gênero a serem desenvolvidas em várias disc ip linas, em vá rios cursos. Podia ser soc iologia, a ntro pologia, história, história da Itá lia, enfim, vá rias disc ip linas. O que queria esse grupo? Que os estudantes pudessem substituir uma parte do programa institucional de ca da ma téria poresses seminários de gênero. Então, tratava-se de uma oferta livre de aulas, ou de um certo número de aulas, que poderiam ser de quatro horas, como de dez horas, dentro das atividades de ensino oficial da faculdade. Cada titular podia escolher uma das nossa stemática se intro duzi-la no seu curso. Esse foi um tra balho imenso, porque realmente a gente não estava a costumada a esse tipo de coisa, mas era uma época em que se podia fazer, porque está va mos no velho sistema universitá rio ita lia no, em que a didática era feita muito com seminários, grupos de trabalho... Agora não se pode ma is, porcausa da reforma (a nossa universidade se uniformizou, digamos, com os padrões europeus, três níveis de ensino: o primeiro grau, três anos; o mestrado, dois anos; e o doutorado). Antes não era assim. A nossa tese de graduação valia em nível intemacional como uma tese de mestrado, porque eram quatro anos de cursos, ma is uma tese que freqüentemente toma va outro a no ou ma is de pesquisa. Então, naquela época podia-se fazer muitos seminários. Agora não seria mais possível. Esse grupo teve muitos problemas, mas foi muito combativo, e se baseava funda menta Imente no ensino. Uma a miga minha que era uma historiadora da situação da mulher na Segunda e na Terceira Internacional muitas vezes me convidou, e eu dizia que não, porque eu nunca tinha estudado a história das mulheres.

Acho que esse é um percurso que tem sido seguido pormuitas de nós, não é? No início negamos dizendo: "Nunca estudei esse tema, não posso dar um curso assim". Mas as colegas feministas me explicavam que eu podia, numa aula, tentar 
ver as coisas com outro olhar. E no final eu aceitei. Pelo que me lembro, meus dois primeiros temas foram migrações femininase a representa ção do corpo das mulheres indíg enas. Então entrei num grupo de colegas que já estavam a va nçando nesse sentido, que tinham relações internaciona is referentes a o discurso da história de gênero. Aquele era justamente o momento em que na Itália estavam abandonando o estudo da mulher e priorizando o estudo do gênero. Ainda é um percurso que não me parece acabado, pois eu vejo nas revistas que se escreve sempre sobre história das mulheres. Aliás, o meu primeiro livro tratou de história das mulheres, também. Era sobre a formação do mercado de trabalho paulista desde 1850 até 1930 , na transição do trabalho esc ravo para o trabalho livre. Eu estudei a oferta e a procura de mãode-obra, as dinâmicas do salário e a mobilidade da força de trabalho, e dediquei um capítulo sobre as mulheres no mercado de trabalho paulista. Esc revi esse livro entre 1977 e 1979, o que acabou sendo uma das primeiras análises que focaliza ram as mulheres no Brasil.

Porém, se vocês me tivessem perguntado naquele momento se eu estava fazendo história das mulheres, eu teria dito que não, que o meu problema era estudaro mercado de trabalho, ver em que posição esta va $m$ as mulheres nesse contexto. Mas o conta to com essa scolegas de que lhes falei e a abordagem multid isc ip linarde Temáticas Femininas me estimula ra m muito, sem dúvida. Inclusive me deu uma consciência maior da situa ção feminina na universidade. Porque antes eu pensava que as coisas que me aconteciam, como a marginalização, o mobbing [violência psic ológica no trabalho], forma vam parte do meu roteiro pessoal. Porém, ao ver em manifestações públicas como as colegas tratavam esse tipo de matéria (e como eram tratadas pelos colegas homens), eu tive um choque. Havia um verdadeiro enfrentamento na faculdade. Isso continuou quando se instituiu um centro interd epartamental de estudos das mulheres, o CIRSDe, do qual eu participei de forma marginal de sua organização, mas cheguei a ser do comitê diretivo, etc.

O meu interesse em relação aos estudos de gênero nasceu, então, em uma situa ção de relações profissiona is. Foi isso que me levou a achar que o estudo das mulheres fosse um tema interessante. Por quê? Porque eu antes pensava que a história das mulheres era um assunto e não uma problemática. Essa era a minha crítica. Bom, eu dizia, é um assunto, onde está o problema historiográfico? Trabalhando, sobretudo não tanto com historiadoras, mas com antropólogas, entendi que essa era uma problemática, e bastante rapidamente eu vi que, no campo da história social, essa a tenção para as relações de gênero era um aspecto fundamental. 
Como disse, eu já tinha trabalhado sobre essas relações no meu primeiro livro, porque, a a nalisar a colocação das mulheres no mercado de trabalho paulista, eu evidenciei a situação da mulher imigrada na fazenda, e constatei que ela fazia um trabalho que não custava nada, que não tinha um salário, mas que garantia a reprodução da família, como já havia apontado José de Souza Martins no seu O cativeiro da terra. Era o trabalho das mulheres na roça, na pequena criação, que dava a possibilidade de sustentara família a té o recebimento da remuneração para a colheita do café.

E na passagem da fazenda à fábrica paulista percebi que a mulher na fábrica passou a ser pensada como uma pessoa frágil, que precisava de proteção. Na fazenda, entretanto, ela sofria toda uma série de violências físicas, inclusive sexua is $(0$ jomal Fanfulla é uma ótima fonte para esse tema), e essas violências na fazenda não eram apresentadas como um sintoma da fragilidade da mulher. No momento em que a mulher passou a trabalhar na fábrica, ela passou a ser representada como frágil e exposta a todo perigo. Então eu já tinha feito esse trabalho em relação às mulheres no Brasil, e me parecia, nesse contexto, fundamental, porque para entender o mercado de trabalho eu tinha de enfrentar esse problema. Assim, continuei trabalhando sobre o corpo das mulheres, o corpo das mulheres indíg enas, e sobre mig ração.

Cristina Scheibe Wolff: Então, a sua a proximação com a questão de gênero já vem dentro da sua preocupação com o Brasil, como brasilianista?

Joana: Como você se tomou brasilianista?

Chiara: Na verdade eu me tomei latino-americanista. Desde os anos 60, quando eu esta va no colégio e era a diretora do jomal do liceu. Então pensei uma outra produção editorial, editei por minha conta cadernos temáticos, que depois ia vender. Chamei a coleção Quaderni di Gruppo, para evidenciar que era o resultado de grupos de estudos autônomos. Eu organizava um grupo de estudo, escrevíamos nossos pequenos ensaios, e depois eu ia vender nas livrarias. Havia coleta de publicidade para financiar, era um trabalho muito interessante, mas ta mbém era um trabalho muito pesado, porque o diretor do meu liceu ameaçou de me expulsar da escola (de todosos lic eus da Itá lia, foi a a meaça ma is ra dic al!) por causa da minha atividade editorial. Um desses cademos foi sobre América Latina. Então, antes de entrar na universidade, eu já tinha esse interesse... Eu não queria fazera carreira universitária, queria trabalhar nas organizações internacionais, e já tinha feito um curso em Genebra. Queria estudar ta mbém a história, ou da África ou da América Latina, 
enqua nto continentes de passa do colonial. Mas era muito ma is interessada pela América Latina, pela longa relação com a Europa, pelas línguas, porque eu adorava o espanhol... Eu tenho uma formação clássica, estudei grego, latim, filosofia, como tantos italianos, então era interessa da por esse elo entre a Europa e a América, no momento da Renascença. Parecia ser muito interessante estudar uma ligação que era de longa duração. No primeiro ano da universidade tive a sorte de freqüenta ro primeiro curso de América Latina. Então comecei com esse curso, e no final decidi fazer a tese sobre o assunto porque eu sempre adorei estudar história, uma das matérias de que eu mais gostava. E me parecia que a história da América Latina não fosse ligada aos preconceitos da história na cional. Meu orienta dor, Ma rc ello Ca rma gnani, tinha recémchegado de Parise se formara com Femand Braudel e Ruggiero Romano. Parecia-me que no estudo da história da América Latina a gente podia ser ma is livre. Não havia aquelas ca teg orias da história nacional, o Risorgimento, o Fascismo, a Resistência, a classe operária, etc... Eram temas muito interessantes, mas que se tinha que estudar com regras muito definidas. Para mim a história da Améric a La tina era um âmbito em que eu podia estudar o que me interessava e numa perspectiva intemacional, sem esses laços, essa estrutura que meus companheiros da unviersidade tinham, porque havia professores que diziam: este tema pode-se estudar, este não. Comec ei trabalhando com história econômica, sendo minha tese sobre migração e ciclos econômicos na Argentina e no Brasil. Fazendo a tese já pensei em continuar a carreira acadêmica, e de continuar estudando sobre a Argentina. Eu sabia bastante bem o espanhol, e tinha toda intenção de ir para a Argentina para continuar meus estudos, mas os resultados da minha tese me orientaram ma is sobre o Brasil. Porque no caso da Argentina havia uma relação quase perfeita entre as va rá veis que a na lisa va, a imig raçãa, a importação e exportação de mercadorias e a inversão de capitais estrangeiros. Parecia que todos esses elementos tivessem um andamento coerente. Para o Brasil nada funcionava. Então comecei a pensaro porquê disso. A hipótese com que conclui minha tese foi que era a questão da escravidão e do tipo de orga nização da produção na fazenda que fazia com que todas essas variá veis econômicas e socia is não seguissem um andamento parecido, entrelaçadas entre si.

Então me apaixonei pelo tema, pois me parecia que a história do Brasil fosse muito mais complicada e interessante. Fiz um curso de português, ganheiuma bolsa do CNR (o CNPq italiano) e cheguei ao Brasil em 1977.

Joana: Quanto tempo ficaste aqui? 
Chiara: Na primeira vez um ano.

Joana: Tu chegaste a ter algum contato com o movimento feminista da Itália?

Chiara: Não.

Joana: Nenhum?

Chiara: Não, eu era bastante engaja da politicamente...

Joana: Engajada em quê?

Chiara: Era m ativida des de partido. Muito jovem, 17 anos, me assoc iei ao Partido Socialista. Entã o, no momento em que surg iu o movimento feminista na Itália eu atuava em outro contexto político. Tinha a idéia de que era preciso, antes de conseguir os direitos da pessoa, precisava...

Joana: Fazer o socialismo.

Chiara: Exa tamente. Não, não era tã o a ssim, mas no contexto geral da luta política era... Todos juntos, homens e mulheres, não é? Ainda que eu tivesse muitos problemas como mulher na minha atividade política.

Joana: Chegaste a partic ipar de algum grupo de consciência, tiveste notícia da existência de algum?

Chiara: Não, eu não gostava. Eu entendia as razões delas, mas não participava.

Joana: Mas havia na época.

Chiara: Havia, sem dúvida havia. Você sabia que em Turim existe um a té hoje, o último sobrevivente?

Joana: Até hoje?

Chiara: Sim. Uma amiga minha, que muito colaborou com o Projeto Mujeres, se há a reunião do grupo, ela não está para ninguém, fica no grupo, é muito bonito. Elas se reúnem, não sei, uma vez por mês. E continua...

Joana: Por que na Itália foi muito forte também o feminismo da diferença, não foi? Tens alguma notícia a esse respeito?

Chiara: Não. Eu comecei realmente a pensar nesses temas em relação ao meu trabalho. E vendo como era importante 
no meu trabalho. Depois a minha situação profissional foi tal que eu entendi que o feminismo tinha razão. Mas nesse momento já estava trabalhando. No tempo da universidade, dos estudos, eu não era interessa da, na verda de era contrá ria ao feminismo. Entrando no mundo da universidade minhas idéias mudaram, e também o movimento feminista estava mudando. Então, as coisas foram mudando, isso é importante.

Joana: Chiara, quero perguntar sobre os estudos de gênero na Itália. Se você pudesse falar um pouco sobre isso, como está, o que existe. E se tu tens alguma participação nesse campo de estudos, qual é a tua participação?

Chiara: Neste momento eu não tenho uma participação específica, a não serquando sou convida da a alguma reunião falando sobre questões de gênero, e sobre as questões das migrações...

Joana: Tu és reconhecida como especialista em migra ções e em América Latina.

Chiara: Sim, e nesse âmbito eu trabalho com gênero. Mas não participo ma is de instituições a ca dêmic as ou associa ções que sejam estritamente ligadas com gênero. Eu participei de muitas, mas agora não. A mais importante associação de historiadoras, na Itália, é a SIS, Società Italiana delle Storiche, fundada em 1989, que tem uma atividade muito vasta (congressos a nua is, seminários, publicações...), e que desde 2002 publica uma revista, Genesis, da qual fui do comitê editorial por três anos. A SIS organiza também uma escola de verão para mulheres, com bolsa de estudos para jovens. Eu participei de uma dessas sessões, e foi muito bom. Naquele tempo a escola tinha duas sessões de uma semana cada uma, e a cada a no oscursoseram dedic a dosa um tema específic 0 , como gênero e guerra, gênero e relações raciais...

Joana: Quando acontecem? É nas férias?

Chiara: É nas férias. Acontece, se não me engano, na primeira quinzena do mês de agosto. É muito interessante. Agora está em Fiesole, perto de Florença, na sede do centro de estudos da CISL [Confederazione Italiana Sindacati dei Lavora tori], um dos três maiores sindicados italianos.

Joana: Quantos dias dura?

Chiara: Uma ou duas semanas. É realmente uma experiência que eu aconselho, porque é muito bom. Quando eu estive gostei muito, a presentei um seminá rio sobre gênero e relações 
racia is no Brasil, e o lugar ta mbém ga ra ntia uma inter-relação entre as pessoas muito intensa. Havia o curso propriamente dito, seminários e mesas, ótimo, realmente. No site da SIS [www.societadellestoriche.it] você encontra as informações. Sempre para historiadoras, há também a nova revista telemática Storia delle Donne, dirigida por Dinora Corsi, da Universidade de Florença. Estão preparando o terceiro número.

Joana: O gênero passou a ser discutido com facilidade na Itália? Porque aqui no Brasil há algumas disputas: feminismo, gênero, história das mulheres... O que é que tu vês disso tudo, na Itália?

Chiara: Na universidade?

Joana: Isso, nas universidades.

Chiara: Acho que o roteiro que eu fiz muitas fizeram. Há uma parte das colegas que se formaram no feminismo e tiveram uma militância, mas é uma parte muito pequena. A maioria são pessoas como eu, historiadoras, que se a proxima ram aos poucos da temática. Então a cho, antropologicamente, que há uma distinção. Não é tão fácil se comunicar. Mas o problema de fund o é outro: a não sernasfaculdades de letras e de línguas, as mulheres nos níveis ma is altos da academia quase não existem. Eu trabalhei na Facultade de Ciências Políticas (agora estou na Faculdade de Línguas e Literaturas Estrangeiras), onde por muitos anos só uma mulher era ca ted rátic a. Então era muito complica do ter visibilida de. Ainda mais, era muito difícil que uma mulher se envolvesse em temáticas de mulher. Passou bastante tempo...

Joana: O bastante tempo que tu dizes é quanto?

Chiara: Metade dos anos $90 \ldots$

Joana: Metade dos anos 90 , que começou...

Chiara: Começou a ser... Havia pioneiras nessas coisas, mas começou a ser normal falar de mulheres em um curso na universid ade.

Joana: E o gênero? A categoria?

Chiara: A categoria "gênero" é mais complicada, porque de fa to não é tão difundida... Não em nível de pesquisa, mas em nível de ensino, enfim, não é tão assim...

Joana: Menos ainda que "mulher"? 
Chiara: Sim, sem dúvida. E gênero é identific a d o com mulher, norma Imente tem essa identifica ção. É bastante difícil que nos estudos se faça uma análise dinâmica. Eu vejo, por exemplo, nos congressos: é difícil que se faça essa análise dinâmica de gênero.

Joana: A categoria, então, seria pouco usada ainda...

Chiara: Não, a categoria é usada. Mas não sei com quais resultados concretos.

Joana: Muito ma is como se fosse sinônimo de mulher?

Chiara: É. Essa é a minha percepção, não sendo uma especialista de gênero. Nesse caso seria melhorfalarcom uma pessoa que realmente estude só esse tema.

Cristina: Mas podias falar um pouco sobre o Projeto Mujeres, não é?

Chiara: O Projeto Mujeres nasceu em 1995, pela iniciativa dessa ONG italiana que se chama ISCOS [Istituto Sindacale perla Cooperazione allo Sviluppo]. Trata-se da ONG da CISL. A CISL e o ISCOS têm uma ligação de larga duração com a América Latina. Eles organizaram cursos para sindic alistas, cursos de especializa ção para computação em Porto Alegre, várias coisas. Eram bastante comprometidos com a América Latina, a partir da experiência de Allende e depois do golpe de Pinochet. Esendo eu uma das poucas latino-a meric anistas na Itália, chamaram-me para organizar um grupo de trabalho sobre as mulheres latino-a meric a nas. Inc lusive porque naquele momento tinham começado um trabalho com as mulheres sindicalistas da Colômbia. Então com todas essas iniciativas espalhadas, eles queriam reuni-las, para contextua lizá-las, organizá-la s em função da temátic a forte das mulheres, porque eles pensavam que era essa a temátic a com a qual queriam traba lharna América Latina, sobretudo a tra vés da experiência da Colômbia. A idéia deles era de conseguir um grupo de trabalho italiano que fosse um ponto de referência e de informação sobre as mulheres latino-americanas. Eu propus fazer ao contrário: um grupo de mulheres latino-americanas que dessem informações, sugestões sobre o conhecimento das mulheres na América Latina. Em pouco tempo, uma hora, duas horas, já organizamos com o então diretor do ISCOS, Carlo Daghino, as idéias de fundo: uma rede intemacional, européia e latino-americana, sobre os estudos das mulheres. 0 tema era mulher, não o gênero. No discurso não entrava a questão do gênero. Era a mulher. Então, começa mos fazendo um noticiário que era a base... No noticiário nós recolhemos 
toda s a s informa ções so bre as a tivida des da sintegra ntes. E as integrantes eram italianas, espanholas, belgas, brasileiras, a rgentinas, e a lgumas dospaíses and inos. Nunc a conseguimos comunicar-nos realmente com a América Central. Isso foi sempre um problema. Temos integrantes mexicanas, por exemplo, mas não há uma rede lá. Não sei o porquê dessa falta de comunicação. E o grupo se formou e ficou bastante grande. São 150 integrantes, que enviaram informa ções para o noticiário, e que agora deverão enviar notícias para o site, que se formou agora, e nós organizamos vários encontros públic os e oferec emos bolsas de estudos. Conseguimos umas bolsas de estudos para pós-graduados e várias atividades ligadasa todasastemáticas da mulher, na universidade e nas instituições loca is. Na universidade nós fizemos vários seminá rios, ta mbém com historia dora s e cientistas da América do Norte, por exemplo, para fazer comparações, e convida mos bastante gente. Existe ta mbém esse projeto com as sind ica listas colombianas que continua há alguns anos.

A um certo ponto decidimosintroduzirno notic iá rio um pequeno ensaio, que não tinha de sermuito grande, dezpáginas, sobre a stemátic asfeminina sliga das à América La tina. Entã o o Projeto Mujeres agora tem 11 anos, e acho que alcançou vários resulta dos positivos, entre os qua is uma ma iora gregação entre as pessoas dentro do Projeto. Por exemplo, foi importante o convênio com o Centro Interdisciplinar das Mulheres da Universidade de Rosario, na Argentina, o convênio com a UNISINOS de São Leopoldo, que de alguma maneira reforçaram as temáticas e a visibilida de dos estudos de gênero. Consta tei resultados nas relações entre as (e os) integrantes de Mujeres, e a lém de nosso círculo. Por exemplo, o noticiário serviu para uma colega estadunidense desenvolver uma parte da pesquisa dela, sobre imigração, nacionalismo e nacionalidade, estendendo essas problemáticas também à Améric a La tina. O utro exemplo: o notic iá rio foi utiliza do na Itália para encontrar pessoas, pa ra serem convidadas a seminários ou congressos. O que eu lamento um pouco é que nem sempre essa s forma de a grega ção e os convites fora m comunic a dos a o Projeto Mujeres, a o Noticiá rio. Talvez pela falta de tempo, a gente não comunica, mas bastavam duas linhas, não é? Isso falta um pouco. Porque essa sma iores informa ções seria $m$ uma maneira para fazer crescer o Projeto, inclusive.

E agora abandonamos o noticiário pelo site, e eu espero de a lguma forma retomara parte impressa, não mais um notic iá rio nem uma revista, porque você sabe muito bem o que é o compromisso de uma revista, e então pensaria na public ação de cademos temáticos... Na Itália sou fundadora e diretora de uma coleção que se chama L'Estremo Occidente, publicada pela casa editora Città Aperta de Troina, na Sicília. Trata-se de breves ensaios sobre a América Latina, no sentido 
do gênero. Acabamos de publicar agora um livro de Maria Luiza Marcílio, que foi a fundadora da escola de demografia histórica na USP. O livro é sobre a infância abandonada no Brasil, nos séculos XVIII e XIX, e teve muito sucesso na Itália. Outro volume da coleção dedic a do às mulheresé o de Ca milla Cattarulla e llaria Magani, sobre as mulheres imigrantes européias na Argentina, a través da mais recente literatura argentina... E publicamos quatro ensaios sobre o México (Supervivencias de un mundo mágico) de Laurette Séjourné, uma arqueóloga e a ntropóloga muito inovadora, que faleceu há pouco, em 2003.

0 último filhinho, por assim dizer, de Mujeres é o a rquivo que se chama Audio-archivio delle migrazioni tra Europa e America Latina. A sua denominação curta é AREIA e é ligado à minha cátedra de História da América Latina, onde, com meus a lunos, estou recolhendo, deposita ndo entrevista s so b re as migrações históricas da Europa a té a América Latina, e as migra ções contemporâneas da América La tina a té a Europa, de forma particular na Itália, mas também na Espanha, e entrevistas sobre as migrações internas, sobretudo as migrações femininas - migrações internas campo-cidade, ou migrações entre diferentes países la tino-americanos.

Cristina: Agora nos últimos tempos eu tenho ouvido bastante, tem saído aqui na televisão e nos jomais, que muitas das mulheres brasileira s que fa zem essa mig ração estão envolvidas em redes de tráfico. Eles chamam aqui de escravas brancas, redes de prostituição. Você vem trabalhando com isso?

Chiara: Não, eu gostaria de trabalhar, mas a té agora não encontrei a via para fazê-lo, porque isso precisa de uma equipe. Pa ra uma historia dora é difíc il entrevista $r$ as prostitutas na rua, sendo necessária uma estratégia de aproximação. Parece mais um trabalho pa ra sociólogos, a ntropólogos. Olha, a imagem da mulher prostituta latino-americana na Itália apresentou-se já no começo dos anos 80 , quando a imigração ainda era pouca. Geralmente o estereótipo da prostituta era justamente ou a brasileira ou a dominicana. Que isso corresponda a uma situação de fa to, nã o é tão evidente. Cla ro que há mulhere homem. No caso dos brasileiros, há mulheres e homens; no caso das dominicanas são só mulheres. Mas isso não é muito difundido ainda porque as grandesmigrações, os grupos étnicos, os grupos naciona is ma is envolvidos na prostituição são outros, porque existem orga niza ções criminosas de outros países europeus. Do Brasil eu nunca escutei sobre organização criminosa de importação de mulheres para prostituição. As notícias que estão nos joma is são ma is de mulheres que organizam autonomamente o que nós 
chamamos de casas de encontros. Na Itália não há uma regulamenta ção disso, como na Alemanha. Na Itália as casas de prostituição são fora-da-lei. Mas eu a cho, pelos trabalhos que se fazem, que há uma imigração bra sileira muito integrada vinda da classe média, e que não é tão visível, porque se espa lha, mimetiza-se. As a ssocia ções de imigra ntes bra sileiros, como dos argentinos, ou dos peruanos, dos equatorianos, funcionam - eu acompanhei bastante - no momento da chegada. Então se reúnem, fazem essas associações de a miza de, Bra sil-Itá lia, Argentina-Itá lia, promovendo a tivida des culturais, que é uma maneira para se ajudar, e para se propor para outras coisas, para conhecer o país, para se oferecer para traduções, ou entrar no comércio. No momento em que as pessoas encontram trabalho, as a ssociações...

Cristina: Se desmancham.

Chiara: Não só. Há tensões muito fortes nessas associações. Eu gostaria de encontrar uma aluna que trabalhasse sobre isso, porque é muito interessante. A associação se divide, depois se divide outra vez, existem brigas muito fortes e dali a pouco não existem mais. E então é uma imigração que não se reconhece como identidade, a não ser nas festas. É uma imigração que especificamente não se diferencia da população italiana, como a imigração africana, em que imediatamente a gente já identifica, pelo corpo, a pessoa como imigrante. Com os brasileiros fic a muito ma is difícil, como você pode imaginar...

Cristina: Muitos são desc endentes de italianos...

Chiara: Sim, também, mas não só. Bom, a maioria dos bra sileiros tem ascendentes ita lia nos em família, a maioria dos ita lia nos tem a ntepa ssa dos imig ra ntes, então é fá cil. Ma s não me parece que seja esta a auto-representação dos brasileiros na Itá lia. 0 discurso pode ta mbém chega rnisso, "a h sim, minha a vó era..." Mas não é tanto assim. O grupo mais forte, ma is numeroso, está em Milão, se interessam pelo comércio, pelo espetáculo. Com referência à prostituição, nós temos problemas, muito graves, com asmulheres do Leste e da África.

Joana: Quando eu estava na França, a prostituição do Leste Europeu era tão forte que fazia as outras parecerem invisíveis.

Chiara: Inclusive a italiana. É impressionante.

Joana: Eu queria que tu contasses um pouco sobre as obras que tu tensfeito, um roteiro daspesquisas, no que é que resultou 
isso, o que é que foi publicado. Claro, sempre voltado para a questão das mulheres, o que é que tu publicaste até hoje a esse respeito.

Chiara: Desde o início, como eu contava, havia esse interesse pelas mulheres nas relações de trabalho. Depois, o mais importante que escrevi sobre as mulheres é sem dúvida o livro que publiquei em 1999, Terra, etnie, migrazioni. Tre donne nel Brasile contemporaneo. Eu tinha recolhido várias entrevistas com mulheres e homens, para indagar sobre a identidade brasileira. Esc olhi as histórias de vida de três mulheres, que me pareciam ter roteiros exemplares, trabalha ndo com a relação delas com a terra, a relação com a imigração e a relação com a pertença racial, no sentido da aparência física. Este terc eiro tema eu não pensa va enfrentá-lo de início nas minhas pesquisas, mas na realidade todas as entrevistas, inclusive as que não utilizei para este livro, chega ra m a este ponto central, o da raça. Então foram as depoentes que me levaram a trabalhar sobre o tema da raça. O livro apresenta essas três histórias de vida, de duas mulheres brasileiras e uma mulher ita lia na imigra da para o Brasil em 1954. Atra vés dessa s histórias de vida, eu pesquisei a relação com a terra, como forma de auto-representação, como uma maneira de se colocar socialmente. Uma das testemunhas se apresenta como descendente de fazendeiro (uma relação forte com a terra, bem colocada socialmente); outra, a italiana, não tinha na terra um elemento de auto-representação, não obstante o pai dela tivesse comprado uma fazenda antes de emigrarpara o Brasil. A terceira mulherse a presentava como uma mulher sem terra, no sentido de uma mulher muito móvel no território, que seguia as migrações do pai, homem de fronteira. Outra problemática do livro é a migração, nas diferentes formas, interna e externa, migração apresentada pelas três mulheres como um aspecto funda mental da brasilida de, mas ao mesmo tempo como uma maneira de se afirmar e de construir a própria personalidade. Para todas essas três mulheres, a migração importante é a do campo para a cidade, com roteiros distintos. São três mulheres da classe média que encontram na migração para a grande cidade, São Paulo, o trabalho e a realização pessoal.

Como a parência, uma é branca e loira, outra é ma is escura e uma é negra. Então aqui entra o terceiro nível da pesquisa, que é a aparência física e a sua influência nas relações afetivas, familia rese sociais. Eo corpo como mapa dasorigens. Eu trabalhei sobre tudo isso utilizando nos depoimentos tudo que era apresentação do corpo. E no desenvolvimento dessa problemática me achei em uma posição de alguma maneira privilegia da, porque eu era uma historiadora estrangeira à qual 
todas as depoentes explic avam o Brasil, e forneciam uma história do Brasil. Foi muito interessante, porque, vocês sabem, cada depoente utiliza a entrevista, gerencia a entrevista... Segundo sua personalidade e seus objetivos. Assim, há a quela que é professora, e explica tudo, e quer que a entrevista, e a pesquisa, seja dela mesma, e tem a outra (a que se apresentou como uma mulher de fronteira) que, no momento de narrar, não fala mais, porque pensa que a vida dela não tem nenhuma importância, então: "Você é historiadora, você conhece, você é professora da universida de, e eu o que posso dizer?" E a terceira, a mulherita liana, que tem porcausa disso uma cumplicida de comigo: "Nós somos ita lia nas, nós sa bemos como é esse país, não é?".

Um outro trabalho que foi importante na minha formação é uma pesquisa que eu fiz no interior de São Paulo, num bairro rural do Vale do Ribeira, em 77 e em 86, em dois momentos. Então, na primeira vez, quando eu fiquei bastante tempo fazendo entrevistas, era o perío do da ditadura. Naquela época, como dizia, eu não considerava muito as mulheres na perspectiva das relações de gênero; eu queria fund a menta Imente reconstituir a memória do ba irro, que esta va perto de um antigo quilombo, queria saber se havia memória do quilombo. Quando cheguei pela segunda vez, dez anos depois, eu estava interessada nas relações de gênero. Então fiz ta mbém comparações com a situa ção a ntecedente, e eu também era uma mulher diferente. Tinha outro roteiro. Estava casada, com filho. Eu estava sozinha no bairro, eu sempre fiz minhas viagens de pesquisa sozinha... Então, lá, o trabalho foi muito interessante, porque por um lado era a minha situação de mulher no bairro rural, e poroutro era o estudo da cond ição, das ações das mulheres naquele lugar, num momento muito especial que era a vigília das eleições. Eu escolhi justamente aquele momento de mudança nacional, para estudar seus reflexos em nível local... Assim, observei as dinâmicas entre gênero nos dias antecendentes às primeiras eleições democráticas... E foi uma experiência muito importante para mim, no sentido que foi uma daquelas experiências que modifica m o curso das pesquisas. Pa ra mim a sentrevista s foram isso. Ainda, devo acrescentar, que eu tenho usado poucas das entrevistas que fiz, comecei a fazer entrevistas duas semanas depois que cheguei a o Brasil, em 1977, mas era só porque eu precisava construir uma memória. O Brasil não era meu país, então me faltava não só o idioma, mas me falta vam todas a quelas pequenas referência sque fazem parte de uma memória coletiva. E a gente não pode ir assim perguntando. Com um gravador, a relação é ma is clara, com um sentido bem determina do, sobretudo num período como os anos 70 . Assim, a quela sentrevista s no ba irro rural foram uma experiência muito importante, que se concluíram com um ensa io só, porque 
infelizmente o arquivo do munic íp io desse ba irro foi queima do. Por isso, não pude escrever um trabalho mais amplo, de comparação entre história e memória.

Dentro dos meus escritos sobre gênero e migrações, me interessou muito este tra balho "Gênero e estratég ia s mig ra tórias: mulheres italianas imigrantes no estado do Espírito Santo", porque retomei os estudos estatístic os para individualizar as estratégias migra tórias dentro do núcleo familiar. E de fato as conclusões foram interessantes: as família s procediam a uma escolha na base do gênero, pelo que se referem aos filhos para serem trazidos a o Brasil. Norma Imente deixavam na Itália as filhas adolescentes. Levavam os filhos homens - no caso dos pequenos levavam todos -, mas as filhas adolescentes geralmente ficavam na Itália. Isso me pareceu uma coisa interessante para ser estudada.

O que está me interessando muito agora é esta linha que está em parte indicada com o texto que apresentei em Barcelona há dois anos, "História, memória e transformação do passa do: para um estudo da identidade ítalo-bra sileira". Digamos que é a introdução da minha nova pesquisa, que fundamentalmente se baseará seja sobre entrevistas, seja sobre a produção das "comunidades" de descendentes italianos no Brasil. Então essa é a minha nova perspectiva, no âmbito dos estudos do gênero. O restante da minha produção, mais que a metade, é sobre aspolític a striba is em relação à fronteira de expansão nos séc ulos XVIII e XIX. Não sou uma historia dora das mulheres stric to sensu, então, não sei se minhas reflexões podem ser interessantes.

Cristina: Eu acho que sim, que mostras uma trajetória, de historiadora e de proximidade com as mulheres...

Joana: Nós te agradecemos a entrevista...

Entrevista realizada em 21 de setembro de 2006. 